\title{
Magnitude and Associated Factors of Transactional Sex among High School Students in Debre Markos Town, Northwest Ethiopia
}

\author{
Awraris Wolde Kassa*, Belete Yimer Ayele and Muleta Mekonnen Nikus
}

College of Natural and Computational Sciences, Debre Markos University, Ethiopia

\begin{abstract}
Introduction: Sex driven by material benefits is a challenging public health concern, particularly in Sub-Saharan Africa. Assessing youth's transactional relationships remains the integral part of HIV prevention programs. This study aimed to determine the magnitude and associated factors of self-reported transactional sex engagement among high
\end{abstract} school students in Debre Markos town, Northwest Ethiopia.

Method: A cross-sectional study was conducted between 07 February and 13 May, 2015 on 726 girls identified from randomly selected secondary schools. Data were analyzed using bivariate and multivariate logistic regression to identify the predictors of transactional sex.

Result: Two hundred sixty-two (37.3\%) of the respondents reported having had ever sex at the time of the survey. Out of those sexually active students, $17.6 \%$ reported engaging in transactional sex in the previous one year prior to the survey. After controlling for other covariates, while chewing khat and lack of communication about sexual and reproductive health issues were predictors of increased risk for engagement in transactional sex, higher class level, delayed age at first sex, never watching pornographic material, having regular pocket money and parental supervision were found to be protective factors.

Conclusion: This study has shown that considerable proportion of students engage in transactional sex and they are influenced by multiple socio-demographic/socio-economic and individual behavior characteristics. Programs and services designed to control HIVIAIDS transmission should aim to focus on addressing the context specific female students' HIV risk, and sexual entitlement and promoting gender inequity.

Keywords: Students; Adolescents; Female students; High school; Risky sexual behavior; Transactional sex; Predictors; and STIs/ HIV/ AIDS; Ethiopia

\section{Introduction}

More than one billion people in the world are between the ages of 15 and 24 and most of them live in developing countries. These age group are mostly affected segment of the population by the consequence of risky sexual behaviors [1,2]. Every day, about 500,000 young people, mostly women, are infected with STIs and approximately 80 million women have unintended pregnancies every year worldwide [3,4]. Although in past decades, HIV-prevention programmes focused on risky sexual behavior amongst young people, the continued increase in new cases could be an indication that risk sexual behaviors are still occurring in many communities $[5,6]$. A variety of individual behaviors can be identified as placing persons at risk of contracting sexually transmitted diseases (STD) and unwanted pregnancy. One of such behaviors is sex in exchange for money, gifts, favours or other material benefits [6].

Sex driven by material benefit or status is a public health concern particularly, as a driver of the Sub-Saharan African HIV infection $[7,8]$. In sub-Saharan Africa, an estimated 7,000 new infections per day among those 15- to 24-years-old and infected young women outnumber infected young men 3.6 to one [9]. In Africa, where the majority of new HIV infections are among the young, the risk for girls (aged 15 to 24) compared with boys is two to one. Besides to the increased biological vulnerability, multiple interrelated risk factors comprise of age-disparate relationships, violence within partnerships, inconsistent condom use, number of partners and age at sexual debut have been found to be associated with young women's risk of HIV infection [10-13].
As of other risky sexual behaviors, engagement in transactional sex has also been shown to contribute to the increased rates of unintended pregnancy or contracting STIs including HIV/AIDS, as well as acts of violence from clients /partnerships $[10,14,15]$. While there is a debate in the body of literatures as to the definition of transactional sex, in this study refers to a sexual relationship or act(s), outside of marriage or sex work, structured by the implicit assumption that sex will be exchanged for a wide range of instrumental support such as school fees, transportation or a place to sleep, clothing, material goods or money. There is no up-front negotiation or pre-determined payment in transactional sexual encounters as sex workers. While driven primarily by instrumental intentions, transactional relationships may also include emotional intimacy. It is suggesting socio-economic roles in structuring exchange-based relationships within many increased HIV rates countries, and predominantly men who provide and women who receive these material benefits $[7,8,14]$.

Transactional sex can significantly impact the lives of youth and those around them, it is essential that parents, educators and other concerned adults become aware of the prevalence of this behavior, the

*Corresponding author: Awraris Wolde Kassa, College of Natural and Computational Sciences, Debre Markos University, Ethiopia, Tel: +251916517908; E-mail: awraris.wolde@yahoo.com

Received December 05, 2017; Accepted May 17, 2018; Published May 24, 2018

Citation: Kassa AW, Ayele BY, Nikus M (2018) Magnitude and Associated Factors of Transactional Sex among High School Students in Debre Markos Town, Northwest Ethiopia. J AIDS Clin Res 9: 768. doi: 10.4172/2155-6113.1000768

Copyright: (c) 2018 Kassa AW, et al. This is an open-access article distributed under the terms of the Creative Commons Attribution License, which permits unrestricted use, distribution, and reproduction in any medium, provided the original author and source are credited. 
factors that increase their likelihood, and what can be done to abate or prevent those risks.

Reminiscent of Sub-Saharan Africa, cultural and social norms, gender inequality and harmful traditional practices coupled with lack of access to reproductive health information and services have contribute to the similar sets of vulnerabilities among adolescents and young adults in Ethiopia. Furthermore, the continuous high unemployment rate is exposing young people to diverse social problems, of which exchange sex for food, a place to sleep or school fee due to severe economic constraints. Young females from poorer households are more vulnerable to, with their economic status motivating them to partake in transactional sex and limiting their negotiating power. Thus, increasingly, they are confronted with unwanted pregnancy, sexually transmitted infections including HIV/AIDS and social trauma attached to these problems. Unintended pregnancies still affect the lives of many young girls, forcing them to drop out of school, turn to illegal abortions, and thereby endangering their lives. This is reflected by the highest HIV prevalence in the group 15-24 years $12.1 \%$, (6\% -9 \% among young men aged $15-24$, and $10 \%-13 \%$ among young women in the same age group, as well as the unintended pregnancy rate 101 per 1,000 women [16-21].

In Ethiopia, both men and women living in urban areas are more exposed to HIV/AIDS than those living in rural areas. Similarly, for both sexes it was observed that the prevalence is highest in those with secondary and higher education (11.4 percent for females and 3.8 percent for men) [22-28].

Promoting safer sex among youth can lead to decreases in morbidity and mortality due to unsafe abortion, and sexually transmitted diseases (STDs), including HIV/AIDS, and can slow population growth. Investigation to improve school quality and barriers to school completion can have a big impact on the HIV epidemic [29]. Despite literatures highlighted the public health importance of sex driven by economic exchange as an important contributing factor to the increased rate of HIV infection among youths, transactional relationships (or sex) is an area that has been inadequately studied. To design effective prevention program, it is important to understand the determinants of transactional sex within the psychosocial contexts where these sexual encounters occur. The current study aims to assess grade $9^{\text {th }}-12^{\text {th }}$ school girls' self-reported engagement in transactional sexual relationships across social and demographic characteristics in Debre Markos Town, Ethiopia. Therefore, the result will enable policy makers, program managers and other concerned bodies to design appropriate strategy that will challenge the sex motivated by economic exchange behaviors of this vulnerable group.

\section{Subjects and Methods}

\section{Study setting, population and design}

A cross-sectional study was conducted within a period February 7 to May 13, 2015, in Debre Markos town, Northwest Ethiopia among grade $9^{\text {th }}-12^{\text {th }}$ female students. Debre Markos town is found 300 kilometers Northwest of Addis Ababa (the capital city of Ethiopia). The town is situated at 2420 meters above sea level. The population of Debre Markos is $62,469(29,901$ were males and 32,568 females) with the sex ratio in percentage of $47.8 \%$ and $52.2 \%$ respectively [30].

Regarding to the education, there are fifteen elementary schools and private, two secondary schools, one preparatory school, eight kindergartens, one technical and vocational training college, one Teacher Education college, and one public university. This study will be conducted by involving all high school (Grade $9^{\text {th }} \& 10^{\text {th }}$ ) and preparatory school (Grade $11^{\text {th } ~} 12^{\text {th }}$ ) girls in the town. The total number of the source population $(\mathrm{N})$ was 6164 students; high school $(\mathrm{NH}=4164$ students $)$ and preparatory school ( $\mathrm{NP}=2000$ students) students. Those students who married and pregnant were excluded.

\section{Sample size determination and sampling procedures}

Sample size was calculated using single population proportion by considering the following assumptions: $95 \%$ confidence interval, $5 \%$ margin of error, and $10 \%$ non-response rate, and the proportion of $34.5 \%$ of high school students that had multiple sexual partners from previous study [31]. Thus, a total sample size of 726 was estimated. Two stage sampling technique was employed in order to select the required number of subjects. Number of subjects from each school was determined using the proportional allocation formula: number of subjects from high school, $=4164^{\star} 726 / 6164=490$ students and from preparatory school $=2000^{\star} 726 / 616=236$ students.

From 76 sections of high school (i.e. number of Grade $9^{\text {th }}$ section are 38 and grade $10^{\text {th }}$ are 38 sections) 16 sections was selected (8 sections from each grade) by lottery method. Again by applying simple random sampling (SRS) method 490 students were selected from the selected 16 sections. Average number of student in each section was 55 . And also from 36 sections of preparatory school (i.e. number of Grade $11^{\text {th }}$ sections are 17 and grade $12^{\text {th }}$ are 19 sections) 8 sections was selected (4 sections from each grade) by lottery method. Here also by applying SRS method 236 students were selected from the selected 8 sections. Average number of student in each section was 56. Sampling Frame was list of students based on their assigned code number in their respective schools.

\section{Data collection technique}

Data was collected using pre tested structured self-administered questionnaire prepared in English-language and translated to the local language. Questionnaire was pre tested among high school and preparatory school students in Debre Work town which is one of the nearby towns to Debre Markos by taking $10 \%$ of the sample size, and the result of pre-test was analyzed and necessary modification was made prior to the start of the actual study. Those respondents used for the pre testing were not considered for the main study. The self-administered questionnaires were distributed to female respondents and completed in the private setting in their respective schools. Data was collected by college completed six female data collectors. The data collectors were thoroughly trained on the data collection procedure, and how to correctly deal with the respondents and thoroughly trained supervisors and the principal investigator supervised the data collection process.

\section{Data processing and analysis}

Following the data collections; data entry, cleaning, and editing processes was carried out. The data was entered in to EPI- INFO version 6 and exported to SPSS version 16 for analysis. Then printed frequencies were used to check for outliers and clean data. Descriptive statistics was used to describe the data. Bivaraite and multivariate analysis was used in order to identify the important explanatory variables. Confidence interval of $95 \%$ was used and p-value less than $5 \%$ was considered as statistically significant.

\section{Ethical consideration}

Primarily, ethical clearance was obtained from institutionalized research review board, School of Public Health, University of Gondar. Accordingly, concerned bodies of the respective schools were communicated and permission was obtained. Written consent from parents and then written assents from adolescents were obtained 
Page 3 of 7

after explaining the design, the objective and benefit of the study. Respondents were clearly informed that participation is voluntary. It was further emphasized that their responses are confidential, and had their right to withdraw from the study any time without giving further explanation. Privacy and confidentiality were kept in all data collection procedures.

\section{Results}

\section{Socio-demographic characteristics of respondents}

Seven hundred three female students were completed the survey questionnaire making a response rate of $96.8 \%$. The majority 618 (87.9\%) were aged between 17-19 years with the mean age of 17(SD \pm 1.6) years. About two third (66.5\%) were attending high school (grade $9^{\text {th }}$ and $\left.10^{\text {th }}\right)$ while the remaining $33.5 \%$ were attending preparatory school (grade $11^{\text {th }}$ and $12^{\text {th }}$ ) (Table 1$)$.

\section{Sexual/relationships history of the respondents}

Two hundred sixty-two (37.3\%) of the respondents reported having had ever sex at the time of the survey. Among the sexually active respondents $191(72.9 \%)$ had first sexual intercourse at less than 18 years. The mean age at first sexual intercourse was 16.5 years $(16.5 \pm 1.1)$. Of sexually active girls, $17.6 \%$ reported they had engage in transactional sex (sex exchange for money, material goods or both) (Table 2).

\begin{tabular}{|c|c|c|}
\hline Variable & Frequency & Percentage \\
\hline \multicolumn{3}{|l|}{ Age in years } \\
\hline $14-16$ & 212 & 30.2 \\
\hline $17-19$ & 425 & 60.5 \\
\hline $20-22$ & 57 & 8.1 \\
\hline $23-25$ & 9 & 1.3 \\
\hline \multicolumn{3}{|l|}{ Class level } \\
\hline 9th & 222 & 31.6 \\
\hline 10th & 245 & 34.9 \\
\hline 11th & 118 & 16.8 \\
\hline 12th & 118 & 16.8 \\
\hline \multicolumn{3}{|l|}{ Religion } \\
\hline Orthodox & 672 & 95.6 \\
\hline Muslim & 6 & 0.9 \\
\hline Protestant & 16 & 2.3 \\
\hline Others & 9 & 1.2 \\
\hline \multicolumn{3}{|l|}{ Ethnicity } \\
\hline Amhara & 691 & 98.3 \\
\hline Oromo & 7 & 1 \\
\hline Tigre & 2 & 0.2 \\
\hline Others & 3 & 0.3 \\
\hline \multicolumn{3}{|c|}{ Parental supervision } \\
\hline Never & 75 & 10.7 \\
\hline Sometimes & 114 & 16.2 \\
\hline Most of time & 221 & 31.4 \\
\hline Always & 293 & 41.7 \\
\hline \multicolumn{3}{|l|}{ Family residence } \\
\hline Urban & 359 & 51.1 \\
\hline Rural & 344 & 48.9 \\
\hline \multicolumn{3}{|c|}{ Regular pocket money } \\
\hline Yes & 226 & 32.1 \\
\hline No & 477 & 67.9 \\
\hline Use of cell phon & & \\
\hline
\end{tabular}

Table 1: Socio-demographic characteristics of respondents in Debre Markos, North-West Ethiopia, $2015(\mathrm{n}=703)$.

\begin{tabular}{|c|c|c|}
\hline Variables & Frequency & Percentage \\
\hline \multicolumn{3}{|l|}{ Age at first sex } \\
\hline$<18$ & 191 & 72.9 \\
\hline$\geq 18$ & 71 & 27.1 \\
\hline \multicolumn{3}{|c|}{ Currently have a boyfriend/partner } \\
\hline Yes & 98 & 37.4 \\
\hline No & 164 & 62.6 \\
\hline \multicolumn{3}{|c|}{ Relationship with current partner } \\
\hline Main/primary partner & 154 & 58.8 \\
\hline Casual partner & 108 & 41.2 \\
\hline \multicolumn{3}{|l|}{ Lifetime sexual partners } \\
\hline 1 & 143 & 54.6 \\
\hline$\geq 2$ & 119 & 45.4 \\
\hline \multicolumn{3}{|l|}{ Transactional sex } \\
\hline Yes & 46 & 17.6 \\
\hline No & 216 & 82.4 \\
\hline \multicolumn{3}{|l|}{ Ever had pregnancy } \\
\hline Yes & 21 & 8 \\
\hline No & 241 & 92 \\
\hline \multicolumn{3}{|l|}{ Ever had an abortion } \\
\hline Yes & 19 & 7.3 \\
\hline No & 243 & 92.7 \\
\hline \multicolumn{3}{|l|}{ Use of $\mathrm{HCT}^{*}$ service } \\
\hline Yes & 31 & 11.9 \\
\hline No & 231 & 88.1 \\
\hline \multicolumn{3}{|l|}{ Watching pornography } \\
\hline Yes & 120 & 45.8 \\
\hline No & 142 & 54.2 \\
\hline
\end{tabular}

NB USD 1=Birr 22.45 (based on exchange rate during study period) *HCT, HIV counseling and testing

Table 2: Description of relationships/sexual activities of female students in Debre Markos, North-West Ethiopia, 2015 ( $n=262)$.

\section{Predictors of transactional sex}

From the multiple logistic regression analysis age at first sex more than 17 years were found to be about $60 \%$ less likely to have transactional sex. Those students who hadn't communicate about sexual and reproductive health issues with their parent were $66 \%$ more likely to have transactional sex than ever had discussed. And also those who haven't regular pocket money were $51 \%$ more likely to have transactional sex. Chewing khat was 8 times higher to engage in transactional sex than never chewing $[\mathrm{COR}=5.838(2.839,12.00)$, $\mathrm{AOR}=8(4.916,13.31)$ ] (Table 3$)$.

\section{Discussion}

This study aimed to determine the magnitude and associated factors of self-reported transactional sex engagement among high school girls. Of sexually active girls, $17.6 \%$ reported they were engaged in transactional sex in the past 12 months prior to the survey.

This finding is relatively low compared with other prior findings of the country. In North-West Ethiopia, $20 \%$ of sexually active rural high school students have engaged in transactional sex [32]. The national finding of the prevalence of transactional sex among in-school adolescents for Amhara region was $1.5 \%$ which is lower than the current finding $[33,34]$. The finding is high when also compared to another similar study done in Nekemte high school 
Citation: Kassa AW, Ayele BY, Nikus M (2018) Magnitude and Associated Factors of Transactional Sex among High School Students in Debre Markos Town, Northwest Ethiopia. J AIDS Clin Res 9: 768. doi: 10.4172/2155-6113.1000768

Page 4 of 7

\begin{tabular}{|c|c|c|c|c|c|}
\hline \multirow[t]{2}{*}{ Variables } & \multicolumn{3}{|c|}{ Transactional sex } & \multirow[b]{2}{*}{ Crude OR $95 \% \mathrm{Cl}$} & \multirow[b]{2}{*}{ Adjusted OR $95 \% \mathrm{Cl}$} \\
\hline & & & No & & \\
\hline \multicolumn{6}{|l|}{ Age at first sex } \\
\hline$<18$ & 34 & (16.6) & $171(83.4)$ & 1 & 1 \\
\hline$\geq 18$ & 5 & $(8.8)$ & $52(91.2)$ & $0.25(0.15,0.42)$ & $0.40(0.218,0.739)^{*}$ \\
\hline \multicolumn{6}{|l|}{ Parental sexual and } \\
\hline \multicolumn{6}{|l|}{ reproductive health } \\
\hline \multicolumn{6}{|l|}{ communication } \\
\hline Yes & \multicolumn{2}{|c|}{$15(10)$} & $135(90)$ & 1 & 1 \\
\hline No & 24 & (21.4) & $88(78.6)$ & $1.83(1.251,2.672)$ & $1.66(1.072,2.598)^{*}$ \\
\hline \multicolumn{6}{|l|}{ Regular pocket money } \\
\hline No & 20 & (22.9) & $67(77.1)$ & 1 & 1 \\
\hline Yes & 19 & $(10.9)$ & $156(89.1)$ & $0.55(0.373,0.808)$ & $0.51(0.325,0.800)^{*}$ \\
\hline \multicolumn{6}{|l|}{ Type of school } \\
\hline High school & 34 & (16.4) & $173(83.6)$ & 1 & 1 \\
\hline Preparatory school & 5 & $(9.1)$ & $50(90.9)$ & $0.37(0.229,0.590)$ & $0.47(0.278,0.80)^{*}$ \\
\hline \multicolumn{6}{|l|}{ Watching pornography } \\
\hline Yes & 26 & (18.8) & $112(81.2)$ & 1 & 1 \\
\hline No & 13 & (10.5) & $117(89.5)$ & $0.46(0.315,0.68)$ & $0.47(0.303,0.73)^{*}$ \\
\hline \multicolumn{6}{|l|}{ Parental supervision } \\
\hline Never & 14 & $(21.2)$ & $52(78.8)$ & 1 & 1 \\
\hline Sometimes & \multicolumn{2}{|c|}{$8(17.8)$} & $37(82.2)$ & $0.87(0.545,1.395)$ & $0.83(0.469,1.45)$ \\
\hline Mostly & \multicolumn{2}{|c|}{$9(19.6)$} & $37(80.4)$ & $1.16(0.668,2.020))$ & $0.77(0.389,1.52)$ \\
\hline Always & 8 & $(7.6)$ & $97(89.5)$ & $0.44(0.25,0.781)$ & $0.34(0.172,0.65)^{\star}$ \\
\hline \multicolumn{6}{|c|}{ Have sexually active friends } \\
\hline No & 15 & $(11.9)$ & $111(88.1)$ & 1 & 1 \\
\hline Yes & 24 & $(17.6)$ & $112(82.4)$ & $1.71(1.17,5.504)$ & $1.25(0.019,9.64)$ \\
\hline \multicolumn{6}{|l|}{ Chewing Khat** } \\
\hline No & 34 & (19.2) & $143(80.8)$ & 1 & 1 \\
\hline Yes & 5 & $(5.9)$ & $80(94.1)$ & $5.84(2.839,12.00)$ & $8.00(4.916,13.31)^{\star}$ \\
\hline \multicolumn{6}{|l|}{ Alcohol drinking } \\
\hline No & 23 & (20.2) & $91(79.8)$ & 1 & 1 \\
\hline Yes & 16 & $(10.8)$ & $132(89.2)$ & $3.14(1.941,5.062)$ & $1.21(0.649,2.25)$ \\
\hline \multicolumn{6}{|l|}{ Use of cell phone } \\
\hline Yes & 28 & (16.8) & 139 (83.2) & 1 & 1 \\
\hline No & 11 & $(11.6)$ & $84(88.4)$ & $0.62(0.420,0.916)$ & $0.66(0.39,1.099)$ \\
\hline \multicolumn{6}{|l|}{ School performance } \\
\hline Average and above & \multicolumn{2}{|c|}{$6(22.2)$} & $21(77.8)$ & 1 & 1 \\
\hline Below average & 33 & $(14.1)$ & $202(85.9)$ & $5.75(2.426,13.627)$ & $2.46(0.93,6.423)$ \\
\hline \multicolumn{6}{|c|}{ Parental polygamy marriage } \\
\hline Yes & 41 & $(28.7)$ & $102(71.3)$ & 1 & 1 \\
\hline No & 37 & $(31.1)$ & $82(68.9)$ & $0.60(0.372,0.951)$ & $0.87(0.474,1.6)$ \\
\hline \multicolumn{6}{|c|}{ Attending religious Service } \\
\hline Daily & 28 & $(15.5)$ & $153(84.5)$ & 1 & 1 \\
\hline Occasionally & & & $52(85.2)$ & $1.44(0.911,2.286)$ & $1.60(0.892,2.872)$ \\
\hline Never & & & $18(19)$ & $2.11(1.002,4.438)$ & $1.66(0.589,4.65)$ \\
\hline
\end{tabular}

* Significant at p-value $<0.05$

${ }^{* *}$ Khat(catha edulis): an amphetamine like stimulating substance with alkaloid active ingredient, cathinone, cultivating in Ethiopia considered as the illicit drug

Table 3: Predictors of engagement in transactional sex among school girls in Debre Markos, North-West Ethiopia, 2015.

that $7.6 \%$ of sexually active students have reported as though they had engaged in exchange-based sex (transactional sex) [31]. In Dessie rural and urban community based study among youths 15 24 years, the proportion of transactional sex in their life time was $29 \%$ which is as approximately twice as the current finding [35]. However, as compared with similar studies in African countries, the current finding was found to be lower. In Nigerian, the prevalence of transactional sex among sexually active female public high school students was $38.8 \%$ [36]. These differences could be explained by geographical, subjects enrolled, the definition of transactional sex used and other differences between the population involved in our study and the previous studies. 
As the finding of this study, chewing khat found to be positively and significantly associated with transactional sex. This study is in consistent with other studies done in Ethiopia and elsewhere among in- school and out- school youths that substance use increases in risky sexual practices [24,37]. Age at first sex was significantly associated with transactional sex. Those students who had age at first sex more than 17 years were $60 \%$ less likely to engage in transactional sex than those students who had first sex at or less than 17 years in the past 12 months prior to the survey. This is supported with similar studies elsewhere in Ethiopia showed that reported youths who start sexual activities at an early age have a higher number of sexual partners; and are more likely to engage in sex driven by material benefits or money $[25,35,38]$.

Discussing about sexual and reproductive health issues with parents was positively and significantly associated with transactional sex. Those students who had discussed were $60 \%$ less likely to engage in transactional sex than those who hadn't discussed in the previous one year. This is in consistent with previous studies that communication helps to transmit values, beliefs and expectations about sexual and reproductive health matters to their adolescents and consequently, protects the young from engaging in risky sexual practices and associated adverse health consequences $[39,40]$.

In current study type of school found to be significantly associated with transactional sex in the past 12 months prior to the survey. Being preparatory school students was $53 \%$ less likely to engage in transactional sex than high school students. There are findings in international and Ethiopian studies that both support and contradict current study that higher grade level is predictors of decreased risk for engagement in the exchange of sex for money, gifts or both [4145]. This variability of findings may be attributed to various including design, study population involved, and other differences.

And also those students who had always parental monitoring were $66 \%$ less likely to engage in transactional sex than school girls with no parental supervision. This finding was in agreement with the study conducted in Shendi [46]. The most likely explanation is that those who lack familial control and connectedness which can give them to have a sense of freedom to involve in risk sexual behaviors. Not having regular pocket money was found to be a significant predictor of girls' engagement in transaction sex. In this study, adolescents who didn't get regular pocket money $51 \%$ more likely to engage in transaction sex than those who received pocket money from their parent. The result is consistent with earlier study findings $[31,47,48]$. This may be due to lack of pocket money required for subsistence makes young females to be at particular risk of sexual risk taking, with their economic status motivating them to partake in transactional sex to satisfy their economic and material needs.

As compared to those students watching pornographic materials or movies those never watch in the past 12 months were 53\% less likely to engage in transactional sex. This is supported by a study in Addis Ababa and Bangladesh among high schools participants $[35,49,50]$. This could be because adolescents who watch pornographic movies may develop unrealistic attitudes about sex, and loosen up their negotiating power which leads them to engage in exchange- based sexual practice.

Unlike some previous studies, no association was seen between transactional sex and students' school performance, having other sexually active friends, and alcohol drinking [51,52]. This could be due to the differences in the predictors of transactional sex among communities with different sociocultural backgrounds.

It is necessary to take precaution when applying the findings of this study. As most of data on exposure variables were obtained by students self-report and this creates a potential for recall and reporting biases. The fact that the study was limited to high school adolescents who were found at school during the time of data collection was another limitation as it may be difficult to generalize the result to out of school and drop-outs that might have different life experiences. Despite the above limitations, this study takes a valuable step toward identifying adolescents who are at risk of exchange-based sex, as well as avenues for intervention.

\section{Conclusion}

This study has shown that considerable proportion of students engage in transactional sex. The findings indicated that chewing khat and lack communication about sexual and reproductive health issues were predictors of increased risk for engagement in transactional sex, higher class level, delayed age at first sex, never watching pornographic material, having regular pocket money and parental supervision were found to be protective factors.

\section{Recommendation}

Based on the findings of this study, the following important works on contextual psychosocial factors that both encourage and discourage engagement in transactional sex are recommended.

- Emphasis should be given to discouraging alcohol and other drug use amongst the students, especially on chewing khat which was found to be the common and the most contributors for the engagement in transactional sex of the study subject. Legal enforcement on risky places around the schools like control of sexually explicit films showing houses, control of expansion of khat markets and nightclubs.

- Programs designed to control HIV/AIDS transmission should aim to bring about behavioral change and focus on addressing the context specific young women's HIV risk, and sexual entitlement and promoting gender inequity, and accessibility of support programs and services for parents and their children, and age appropriate information, education and communication on HIV transmission and prevention, delaying age of first sexual initiation and contraceptive uses. Increased awareness and expansion of HCT services are required to promote and sustain behavioral change.

- Parents should be involved in HIV/AIDS-related behavioral intervention activities. Behavior change communication campaigns that are sensitive to strong social and cultural norms supporting the relationship between parent and child may make parents more aware of the risks of transactional sex and encourage them to be more involved in their children's decisions.

\section{Authors' Contribution}

All authors, Awraris Wolde, Belete research question, monitored and findings and written the paper.

Yimer, and Muleta Mokonnen conceptualized the managed fieldwork, analyzed and interpreted

\section{Acknowledgment}

We would like to acknowledge Debre Markos health office, educational office for their permission and all necessary support during the data collection period. We are very grateful to all study participants and their families for their willingness and cooperation. We also thank the data collectors for their active participation in data collection. Lastly we would thank all those who assist us during our work. 


\section{References}

1. Senn TE, Carey MP, Vanable PA, Coury-Doniger P, Urban MA (2016) Childhood sexual abuse and sexual risk behavior among men and women attending a sexually transmitted disease clinic. J Consult Clin Psychol 74: 720-731.

2. Okonofua $F(2007)$ New research findings on adolescent reproductive health in Africa. Afr J Reprod Health 11: 7-12.

3. Berhane Y, Yared M, Eleni S, Lawrence G, David W (2008) HIVIAIDS in Ethiopia: An epidemiological synthesis. The World Bank, Washington, DC 27 $-109$.

4. Gupta N, Mahy M (2010) Sexual initiation among adolescent women and men: Trends and differentials in Sub-Saharan Africa. Demographic and Health Research Division, ORC Macro International 145-146.

5. UNFPA TMaCBo, Fund TUNP (2009) Population Growth and Poverty. Fact Sheet.

6. Sonkin B, Hinde A (2007) Defining risky sexual behaviour in the UK: A laten class approach. Southampton, UK, Southampton Statistical Sciences Research Institute.

7. Jewkes R, Morrell R, Sikweyiya Y, Dunkle K, Penn-Kekana L (2012) Transactional relationships and sex with a woman in prostitution: prevalence and patterns in a representative sample of South African men. BMC Public Health 12: 325 .

8. Stoebenau K, Nixon SA, Rubincam C, Willan S, Zembe Y, et al. (2011) More than just talk: The framing of transactional sex and its implications for vulnerability to HIV in Lesotho, Madagascar and South Africa. Globalization and Health 7: 34

9. FHI, USAID, Youth Net Assessment Team (2014) Assessment of youth reproductive health programs in Ethiopia. FHI, Addis Ababa, Ethiopia.

10. Jewkes RK, Dunkle K, Nduna M, Shai N (2010) Intimate partner violence, relationship power inequity, and incidence of HIV infection in young women in South Africa: A cohort study. Lancet 376: 41-48.

11. Ott M, Bärnighausen T, Tanser F, Lurie MN, Newell ML (2011) Age-gaps in sexual partnerships: seeing beyond 'sugar daddies'. AIDS 25: 861-863.

12. Jewkes R, Dunkle K (2012) Transactional sex and HIV incidence in a cohort of young women in the stepping stones trial. J AIDS Clin Res 3.

13. Jama Shai N, Jewkes R, Levin J, Dunkle K, Nduna M (2010) Factors associated with consistent condom use among rural young women in South Africa. AIDS Care 22: 1379-1385

14. Dunkle KL, Jewkes RK, Brown HC, Gray GE, Mclntryre JA, et al. (2004) Transactional sex among women in Soweto, South Africa: prevalence, risk factors and association with HIV infection. Soc Sci Med 59: 1581-1592.

15. Dunkle KL, Jewkes RK, Nduna M, Jama PN, Levin JB, et al. (2007) Transactiona sex and economic exchange with partners among young South African men in the rural Eastern Cape: Prevalence, predictors, and associations with genderbased violence. Soc Sci Med 65: 1235-1248.

16. UNFPA (2011) Maternal mortality figures show limited progress in making motherhood safer.

17. Donenberg GR, Bryant FB, Emerson E, Wilson HW, Pasch KE (2003) Tracing the roots of early sexual debut among adolescents in psychiatric care. J Am Acad Child Adolesc Psychiatry 42: 594-608.

18. Ethiopia Federal Ministry of Health $(\mathrm{MOH})$, National HIVIAIDS Prevention and Control Office (2016) AIDS in Ethiopia, 6th report, Addis Ababa, Ethiopia. Ethiopia Federal Ministry of Health.

19. Scholl E, Schueller J, Gashaw M, Wagaw A, Michael LW (2012) Assessment of Youth Reproductive Health Programs in Ethiopia.

20. Federal HIVIAIDS Prevention and Control Office (2010) Report on progress towards implementation of the UN Declaration of Commitment on HIVIAIDS. Federal Democratic Republic of Ethiopia, 2010.

21. Jason O (2009) Situation analysis on population, reproductive health and gender. UNFPA Country Technical Services Team, Addis Ababa.

22. Hong R, Mishra V, Govindasamy P (2008) Factors associated with prevalen HIV infections among Ethiopian adults: Further analysis of the 2005 Ethiopia demographic and health survey. Macro International Inc, Calverton, Maryland, USA.
23. Central Statistical Agency (2012) Ethiopia demographic and health survey (EDHS)-2011. Addis Ababa Ethiopia.

24. Kebede D, Alem A, Mitike G, Enquselassie F, Berhane F, et al. (2005) Khat and alcohol use and risky sex behaviour among in-school and out-of-school youth in Ethiopia. BMC Public Health 5: 109.

25. Wouhabe M (2007) Sexual behaviour, knowledge and awareness of related reproductive health issues among single youth in Ethiopia. Afr J Reprod Health 11: 14-21.

26. Alemayehu M (2015) Assessment of the Prevalence of Premarital Sex and Unprotected Sexual Practice among Gedeo Zone High School Students, SNNPR, Ethiopia. MPH Thesis, AAU.

27. Fantahun M, Worku S (2006) Unintended pregnancy and induced abortion in a town with accessible FP services. Ethiopian Journal of Health Development 20: 2 .

28. Leigh B, Stall R (2010) Substance use and risky sexual behavior for exposure to HIV: issues in methodology, interpretation, and prevention. American Psychologist 48: 1035-1043.

29. Jukes M (2008) Making the case for education as a health priority in subSaharan Africa. Educational access and HIV prevention 02138: 495-8142.

30. CSA (2011) The 2011 population and housing census of Ethiopia. Results at Country Level, Addis Ababa, Ethiopia, 2011.

31. Seme A, Wirtu D (2008) Premarital sexual practice among school adolescents in Nekemte Town, East Wollega. Ethiop J Health Dev 22: 167-173.

32. Alene GD, Wheeler JG, Grosskurth H (2010) Adolescent reproductive health and awareness of HIV among rural high school students, North Western Ethiopia. Ethiop J Health Dev 16: 57-68.

33. Getnet MK, Damen HM (2011) Level of stigma among female sex workers: comparison of two surveys of HIV behavioral data, Ethiopia. Afr Health Sci 11 543-549.

34. Wouhabe M (2007) Sexual behaviour, knowledge and awareness of related reproductive health issues among single youth in Ethiopia. African Journal of Reproductive Health 11: 14-21.

35. Mazengia F, Worku A (2009) Age at sexual initiation and factors associated with it among youths in North East Ethiopia. Ethiop J Health Dev 23: 156-160.

36. Gail BS, Lucy Lot L, Huang B, Comfort A, Therese M, et al. (2013) Sexual behaviour of adolescents in Nigeria: Cross sectional survey of secondary school students. Bio Med J 326: 3-4.

37. Rudatsikira E, Ogwell AEO, Siziya S, Muula A (2007) The prevalence and associated factors of sexual intercourse among school adolescents in Coast Province, Kenya. Tanzania Health Research Bulletin 9: 161-162.

38. Mosher W, Chandra A, Jones J (2005) Sexual behavior and selected health measures: men and women 15-44 years of age, United States, 2002. Adv Data 15: 1-55.

39. Eisenberg ME, Sieving RE, Bearinger LH, Swain C, Resnick MD (2006) Parents' communication with adolescents about sexual behavior: A missed opportunity for prevention? J Youth Adolesc 35: 893-902.

40. DiClemente RJ, SCD GMW, Crosby R, Cobb BK, Harrington K, et al. (2011) Parent-adolescent communication and sexual risk behaviors among African American adolescent females. J Pediat 139: 407-412.

41. Blanc A (2010) The relationship between sexual behavior and level of education in developing countries. UNAIDS, Geneva.

42. Blanc AK, Way AA (1998) Sexual behavior and contraceptive knowledge and use among adolescents in developing countries. Stud Fam Plann 29: 106-116.

43. Global Campaign for Education (2004) Learning to survive: How education for all would save millions of young from HIVIAIDS. Global Campaign for Education, Brussels, Belgium.

44. Gregson S, Mason PR, Garnett GP, Zhuwau T, Nyamukapa CA, et al. (2012) A rural HIV epidemic in Zimbabwe? Findings from a population-based survey. Int J STD AIDS 12: 189-196.

45. Lagarde E, Carael M, Glynn JR, Kanhonou L, Abega SC, et al. (2001) Educational level is associated with condom use within non- spousal partnerships in four cities of sub-Saharan Africa. AIDS 15: 1399-1408.

46. Bogale A (2014) Premarital sexual practice and its predictors among in- 
Citation: Kassa AW, Ayele BY, Nikus M (2018) Magnitude and Associated Factors of Transactional Sex among High School Students in Debre Markos Town, Northwest Ethiopia. J AIDS Clin Res 9: 768. doi: 10.4172/2155-6113.1000768

Page 7 of 7

school youths of Shendi Town ,West Gojjam Zone, North West Ethiopia. BMC Reproductive health 11: 49.

47. Borawski EA, levers-Landis CE, Lovegreen LD, Trapl ES (2003) Parental monitoring, negotiated unsupervised time, and parental trust: The role of perceived parenting practices in adolescent health risk behaviors. J Adolesc Health 33: $60-70$

48. Okafor EE (2010) Child labor dynamics and implications for sustainable development in Nigeria. Journal of Sustainable Development in Africa 12.

49. Berhanu L, Haidar J (2009) Does exposure to sexually explicit films predict sexual activity of the in-school youth? Evidence from Addis Ababa high schools. Ethiopian J Health Dev 23: 183-189.
50. Rahman M, Haseen F, Gazi R (2007) An analysis of social, behavioral and biomedical risk factors of adolescents and youth clients of female sex workers: Implications for STI/HIV/AIDS interventions in Bangladesh Family Health International, Bangladesh Office and Bangladesh Women's Health Coalition. GFATM operations research.

51. Weiser S, Leiter K, Heisler M, McFarland W, Percy-de Korte F, et al. (2006) A population-based study on alcohol and high-risk sexual behaviors in Botswana. PLoS Med 3: e392.

52. Moore AM, Awusabo-Asare K, Madise N, John-Langba J, Kumi-Kyereme A (2007) Coerced first sex among adolescent girls in sub-Saharan Africa: prevalence and context. Afr J Reprod Health 11: 62-82. 